\title{
What Chinese Education Needs
}

Doi:10.5901/jesr.2013.v3n7p230

\section{Fan Chu Shu}

\author{
Student of Saint-Petersburg State University \\ Faculty of philology \\ Email: fcsda1988@gmail.com
}

\begin{abstract}
The issue of nation building and development is cardinal among the goals of any nation. In an attempt to meet the needs of citizens and also be in tune with other developed nations in a dynamic and globalized world, China is currently grappling with a lot of challenges. The place of education cannot be overemphasized. This paper attempts to explore what Chinese education needs urgently, based on the current education situation. It concludes that repositioning the teaching profession to meet developmental challenges in China should be paramount in the mind of all stakeholders. The drive towards making China one of the top developed economies in the world by the year 2020 could be realized if education is highly recognized by the government.
\end{abstract}

Keywords: Chinese education; fair; interest; teaching; love

\section{The Current Situation of Education in China}

Nowadays, governments cannot afford to ignore education, including the Chinese government. In China, education is composed of a six-year primary education, a six-year secondary education and higher education. China offers the first nine years of compulsory education for free, but children need to receive high marks in order to enter into a good junior high school, and then senior high school, and finally, a top university. From preschools to universities, there are different ranks. Thus, since childhood, the sole objective of all Chinese children is to receive the highest level of ranking as possible.

\section{What Chinese Education Needs}

Under the birth control principle, China limits the number of children per family. Therefore, families are not allowed to exceed one child per family. Thus, children are often the focus of the family unit. As a consequence, most children have been spoiled since childhood, and are used to being waited on hand and foot. On the other hand, parents are really strict about their studies -- they care less about their character and moral compass, compared to grades. Finally, when the children leave home and enter society, many serious problems arise. For instance, 1) students are subjected to various requirements, determined by individual provinces, which maintain lower standards for students within their region. This facilitates contention between higher ranking students who quickly become frustrated with their life, their place in the university as well as in society; 2) having been used to good remarks and praise from parents or teachers, they are lost in society and grapple with the true meaning of life; 3) due to overt confidence, long term dependency, and inability to perform daily tasks independently, they are incapable of working in harmony with others. All the examples above showcase that it is vital to pay attention to the needs of Chinese education:

\section{Everyone should Share the Equal Right of Getting Higher Education}

The Household register principle makes lots of Chinese students lose their chance to enter into top universities. There is a well known story in China which recalls the fate of two similar students in which life dealt a very different hand. An engineer and a building worker, took part in the same college entrance examination and received the same grades. However, just because the engineer is from Beijing, and the building worker is from the Hubei province, this resulted in a different fate. The engineer entered into a famous university, while the building worker was unable to attend the same university. Household register principle has given rise to lots of such problems, but everyone should share the equal right of getting higher education. 


\section{Liberation of Humanity}

It is reported that a Chinese team visited America in order to investigate its system of primary education. In their report, they described that there was no distinction of morality and ability between the second grade students who were still illiterate; but they took music, art, and sports seriously instead of mathematics, physical and chemical sciences; classroom discipline was lacking, and students ignored the authority of their teachers. The investigation concluded that American primary education was bad. In the same year, an American team also came to China, and reported that Chinese students were well disciplined. In classes, their hands were always behind their backs unless the teacher asked questions, they did not speak in class. Students were expected to do home work after school; students are ranked by marks. The American team concluded that the grades of Chinese students are the best, and therefore Chinese science culture might surpass America in 20 years. However, 30 years past, the conclusions of these two teams were all wrong. American -style education is increasingly admired, while Chinese-style education has become an object of public denunciation. This anecdote is a fact about the education in China. In fact, the children are being stifled by the preconceptions of family members, teachers and society. No one should force a presupposed role or expectation from them, they should be free to grow and carve their own path in society. Education is not only about knowledge, but more about the liberation of their individual interests and desires. However, our education sees knowledge and discipline as the most important aspect, which glosses over the ability to function as an individual in society.

On the contrary, a survey report shows that $80 \%$ of children are unable to do their laundry, cook or successfully complete housework. Among the young people who are under the age of $18,17 \%$ of them suffer from emotional disorders and behavioral problems. This is especially evident within interpersonal relationships, emotional stability and adaptive ability problems. Many teenagers find it difficult to deal with adversity and disappointments in life and choose to commit suicide to end up all of them. This is the tragedy of an examination-oriented education. Due to the uniqueness of each person in this world, why is it necessary to enforce such rigid roles for children in society? If everybody could find their own interest and make a contribution to their own field, instead of blindly joining the fierce competition to reach the so-called success, then this world will be more peaceful and beautiful.

\section{Give with Love}

In my opinion, it is imperative to let children know the most important rule within the universe is to give with love. When people learn to give unselfishly, they will be completely free and happy. Destiny to human beings is like orbit is to planet, all of them are enclosed in a circle. Whatever we send out will definitely come back to us without failure. From what has been discussed above, we may draw the conclusion that under the condition that every citizen could share an equal higher education, helping children to find their unique interests in life as well as teaching them to learn to give and love selflessly is far more important than forcing them to always get full marks or win a prize, in this way can we change the face of Chinese education.

\section{References}

J. B. Ayodele, B. K. Oyewole. Repositioning the Teaching Profession to Meet Developmental Challenges in Nigeria Learning Chinese in Private Schools

III. Education for Children

Schools at Naval Air Weapons Station China Lake, California

A Day in the Life - Mandarin Chinese 